\title{
The association between body-mass index and patient outcome in septic shock: a retrospective cohort study
}

\author{
Bettina Wurzinger ${ }^{1}$, Martin W. Dünser ${ }^{2}$, Christoph Wohlmuth ${ }^{1}$, Martina C. Deutinger ${ }^{1}$, Hanno Ulmer ${ }^{3}$, \\ Christian Torgersen ${ }^{4}$, Christian A. Schmittinger ${ }^{4}$, Wilhelm Grander ${ }^{5}$, Walter R. Hasibeder ${ }^{1}$ \\ ${ }^{1}$ Department of Anesthesiology and Critical Care Medicine, Krankenhaus der Barmherzigen Schwestern, \\ Ried im Innkreis, Austria \\ ${ }^{2}$ Department of Intensive Care Medicine, Inselspital, Bern, Switzerland \\ ${ }^{3}$ Institute of Medical Statistics, Informatics and Health Economics, Innsbruck Medical University, Innsbruck, Austria \\ ${ }^{4}$ Department of Anesthesiology and Critical Care Medicine, Innsbruck Medical University, Innsbruck, Austria \\ ${ }^{5}$ Department of Internal Medicine, Community Hospital Hall, Hall in Tirol, Austria
}

Received June 25, 2009, accepted after revision July 23, 2009

\section{Der Zusammenhang zwischen dem Body Mass Index und dem Patientenoutcome im septischen Schock: Eine retrospektive Kohortenstudie}

Hintergrund: Es bestehen keine Daten über die Assoziation zwischen dem Body Mass Index (BMI) bzw. BMI Kategorien und der Mortalität von septischen Schockpatienten.

Methoden: Die Datenbank einer interdisziplinären Intensivstation wurde retrospektiv nach erwachsenen Patienten mit septischem Schock durchsucht. Von allen Patienten wurde der BMI, demographische, klinische und laborchemische Parameter gemeinsam mit Outcomevariabeln dokumentiert. Die Studienpatienten wurden wie folgt anhand des BMI kategorisiert: BMI $<18,5 \mathrm{~kg} / \mathrm{m}^{2}$, Untergewicht; BMI 18,5-24,9 kg/m², Normalgewicht; BMI 25-29,9 kg/m², Übergewicht; BMI $>30 \mathrm{~kg} / \mathrm{m}^{2}$, Fettleibigkeit. Bivariate und multivariate logistische Regressionsmodelle wurden verwendet, um den Zusammenhang zwischen dem BMI und Outcomevariabeln zu untersuchen.

Resultate: 301 septische Schockpatienten wurden identifiziert. Der BMI war bivariat mit der Mortalität auf der Intensivstation assoziiert (OR, 0,91; 95\% CI, 0,86-0,98; $p=0,007$ ). Es gab keine signifikante Assoziation zwischen dem BMI und der Mortalität auf der Intensivstation. Allerdings waren höhere BMI Werte trendmässig mit einer niedrigeren Intensivstations-mortalität assoziiert (OR, $0,93 ; 95 \%$ CI, $0,86-1,01 ; p=0,09)$. Während übergewichtige (OR, 0,43; 95\% CI, 0,19-0,98; $p=0,04)$ und fettleibige (OR, 0,28; 95\% CI, 0,08-0,93; $p=0,04$ ) Patienten ein unabhängig niedrigeres Risiko auf der Intensivstation zu versterben hatten als normalgewichtige Patienten, gab es keinen Unterschied im Sterberisiko zwischen normal-

Correspondence: Dr. Martin Dünser, Department of Intensive Care Medicine, Inselspital Bern, Freiburgstrasse, 3010 Bern, Switzerland, E-mail: Martin.Duenser@i-med.ac.at und untergewichtigen Patienten $(p=0,22)$. Ein hoher BMI war unabhängig mit einer geringen Häufigkeit eines akutem Deliriums $(p=0,04)$ und einer geringeren Intensivwieder-aufnahmerate $(p=0,001)$, aber mit mehr Harnwegsinfektionen $(p=0,02)$ assoziiert.

Schlussfolgerung: Bis zu einem BMI von $50 \mathrm{~kg} / \mathrm{m}^{2}$ scheint keine Assoziation zwischen BMI und schlechterem Überleben auf der Intensivstation oder im Krankenhaus bei septischen Schockpatienten zu bestehen. Im Gegenteil, hohe BMI Werte könnten sogar das Risiko am septischen Schock zu versterben reduzieren.

Summary. Background: It is unknown whether bodymass index (BMI) and commonly defined BMI categories are associated with mortality in patients with septic shock.

Methods: The database of a multidisciplinary intensive care unit (ICU) was retrospectively screened for adult patients with septic shock. BMI, demographic, clinical and laboratory variables together with outcome measures were collected in all patients. Subjects were categorized as follows: underweight, $\mathrm{BMI}<18.5$; normal weight, BMI 18.5-24.9; overweight, BMI 25-29.9; obesity, $\mathrm{BMI} \geq 30$. Bivariate and multivariate logistic regression models were used to evaluate the association between BMI and outcome parameters.

Results: In total, 301 patients with septic shock were identified. BMI was bivariately associated with ICU mortality (OR 0.91; 95\% CI 0.86-0.98; $P=0.007$ ). There was no significant association between BMI and ICU mortality in the multivariate model but an increasing BMI tended to be associated with lower ICU mortality (OR 0.93; 95\% CI 0.86-1.01; $P=0.09$ ). Although overweight (OR 0.43; 95\% CI $0.19-0.98 ; P=0.04$ ) and obese (OR 0.28; 95\% CI 0.08-0.93; $P=0.04$ ) patients had an independently lower risk of ICU death than those with normal weight, there was no difference in the risk of 
ICU death between normal weight and underweight patients $(P=0.22)$. A high BMI was independently associated with a lower frequency of acute delirium $(P=0.04)$ and a lower need for ICU re-admission $(P=0.001)$ but with a higher rate of ICU-acquired urinary tract infections $(P=0.02)$.

Conclusions: BMI up to 50 does not appear to be associated with worse ICU and hospital mortality in patients with septic shock. In contrast, a high BMI may reduce the risk of death from septic shock.

Key words: Body mass index, septic shock, mortality, overweight, obesity.

\section{Introduction}

Obesity and sepsis are frequent diseases constituting key risk factors for long- and short-term mortality. According to most recent data, the prevalence of both conditions is rapidly increasing $[1,2]$. In industrialized nations, almost two-thirds of the population are currently considered to suffer from overweight or obesity [3], and sepsis ranges among the top five leading causes of death [4]. Obesity compromises the body's ability to adapt to stress or critical illness and is independently associated with increased morbidity and all-cause mortality [5]. Initial data indicated that obesity is a risk factor for the development of sepsis and septic shock [6], and obese patients with sepsis have been reported to have higher mortality rates than their lean counterparts [7]. Experimental models have provided evidence that obesity may exacerbate sepsis-induced inflammation and microvascular dysfunction in the intestinal tract and brain of rodents $[8,9]$. Nevertheless, it is unknown whether body mass and commonly defined weight categories have an influence on septic shock mortality in humans. The association between body-mass index (BMI) and outcome has been investigated in mixed populations in intensive care units (ICUs) and in patients under mechanical ventilation [10]. Results were controversial, ranging from harmful to absent, with others showing protective effects of obesity on patient outcome in acute and critical illness [10].

This retrospective cohort study evaluated the influence of BMI and commonly defined BMI categories on outcome in 301 critically ill patients with septic shock. We hypothesized that increased BMI is associated with excess mortality in septic shock.

\section{Patients and methods}

The retrospective analysis was based on data from a prospectively collected database in an eight-bed multidisciplinary ICU in a secondary referral hospital. The database was screened for patients with septic shock during the period Jan 2003-Dec 2008. Septic shock was documented in a binary fashion and defined as the presence of arterial hypotension (mean arterial blood pressure $<65-70 \mathrm{mmHg}$ ) requiring norepinephrine infusion despite adequate fluid resuscitation in patients with infection and two or more signs of systemic inflammation [11]. Patients $<18$ years, pregnant women and patients with no documented BMI were excluded from the analysis.

The study protocol was approved by the institutional review board of the Krankenhaus der Barmherzigen Schwestern in Ried im Innkreis. In view of the retrospective design of the study, requirement for written informed consent was waived.

\section{Source of data}

All data included in the analysis were drawn from a standardized institutional database and medical records. The database contains information on patient demographics, premorbidities, the clinical course before and during the ICU stay, ICU scoring systems, infections and complications acquired during the ICU stay, and ICU and hospital outcome variables. The database is maintained by the ICU physicians in charge and undergoes regular quality control by the head of the ICU and external experts. Data such as presence of septic shock are documented on specified data sheets at the bedside and entered into the electronic database after the patient has been discharged from the ICU. The database is not connected to a patient data management system therefore it does not contain real-time vital parameters.

\section{Collection of data}

BMI in both sexes was calculated on ICU admission using the standard formula: $\mathrm{BMI}=$ body mass $(\mathrm{kg}) /$ height*height $\left(\mathrm{m}^{2}\right)$. For calculation, the body mass and height last documented or measured before onset of the critical illness or as determined at the time of hospital admission was used. Study patients were then categorized into BMI groups using currently defined cut-off points as suggested by the World Health Organization [12]: underweight BMI < 18.5; normal weight BMI 18.5-24.9; overweight BMI 25-29.9; obese BMI 30-39.9; morbidly obese $\mathrm{BMI} \geq 40$. Since only nine patients $(3 \%)$ presented with morbid obesity, patients with obesity and morbid obesity were combined into a single group, rendering four BMI categories for statistical analysis.

The following variables were collected in all patients: age, sex, presence of chronic obstructive pulmonary disease, any heart disease, arterial hypertension, chronic renal insufficiency, diabetes mellitus or cancer, origin of sepsis, admission year, and the need for invasive mechanical ventilation or continuous veno-venous hemofiltration during the ICU stay. The simplified acute physiology score (SAPS) II and sequential organ failure assessment (SOFA) score were calculated from the most aberrant clinical and laboratory parameters during the first 24 hours after ICU admission and during the ICU stay, respectively. In addition, length of invasive mechanical ventilation, need for tracheotomy, occurrence of myocardial ischemia, sudden cardiac arrest, acute delirium, critical illness polyneuropathy or ICU-acquired infections (pneumonia, urinary tract infection, catheter-related bloodstream infection), length of ICU stay, ICU mortality, need for re-admission to the ICU and hospital mortality were recorded. If patients had to be re-admitted to the ICU during a single hospital stay or during the study period, only the data collected during the first ICU stay were used for statistical analysis.

Definitions for single premorbidities, certain clinical conditions, and ICU complications and ICU-acquired infections, as applied in this study, are outlined in Table 1.

\section{Study endpoints}

The primary endpoint of the study was investigation of the association between ICU mortality and BMI and different BMI categories in critically ill patients suffering from septic shock. Secondary endpoints were evaluation of the associations between BMI and a) length of invasive mechanical ventilation, b) length of ICU stay, c) maximum SOFA score, d) ICU complications (myocardial ischemia, sudden cardiac arrest, acute delirium, critical illness polyneuropathy), e) ICU-acquired infections (pneumonia, urinary tract infection, catheter-related blood- 
stream infection), f) need for invasive mechanical ventilation, tracheotomy or ICU re-admission, and g) hospital mortality.

\section{Statistical analysis}

The SPSS 12.0.1 software package (SPSS Inc., Chicago, IL) was used for all statistical analyses. Kolmogorov-Smirnov tests

Table 1. Characteristics of the study population, survivors and non-survivors

\begin{tabular}{|c|c|c|c|c|}
\hline & Total & Survivors & $\begin{array}{l}\text { Non- } \\
\text { survivors }\end{array}$ & $P$-value \\
\hline$n$ & 301 & 251 & 50 & \\
\hline Age (years) & $69 \pm 14$ & $68 \pm 15$ & $76 \pm 10$ & $<0.001^{*}$ \\
\hline Male sexn (\%) & $162(53.8)$ & $135(53.8)$ & $27(54)$ & 1 \\
\hline Weight $(\mathrm{kg})$ & $74 \pm 17$ & $75 \pm 17$ & $67 \pm 14$ & $0.002^{*}$ \\
\hline Height (cm) & $167 \pm 9$ & $165 \pm 8$ & $167 \pm 9$ & $0.04^{*}$ \\
\hline$B M I$ & $26 \pm 6$ & $27 \pm 6$ & $24 \pm 4$ & $0.001^{*}$ \\
\hline \multicolumn{5}{|l|}{ Premorbidities n (\%) } \\
\hline COPD & $63(20.9)$ & $50(19.9)$ & $13(26)$ & 0.34 \\
\hline Heart disease & $159(52.8)$ & $124(49.4)$ & $35(70)$ & $0.008^{*}$ \\
\hline Arterial hypertension & $155(51.5)$ & $127(50.6)$ & $28(56)$ & 0.54 \\
\hline CRI & $113(37.5)$ & $82(32.7)$ & $31(62)$ & $<0.001^{*}$ \\
\hline Diabetes mellitus & $59(19.6)$ & $51(20.3)$ & $8(16)$ & 0.56 \\
\hline Cancer & $73(24.3)$ & $63(25.1)$ & $10(20)$ & 0.59 \\
\hline \multicolumn{5}{|l|}{ Origin of Sepsis $\mathrm{n}(\%)$} \\
\hline Abdomen & $202(67.1)$ & $164(65.3)$ & $38(76)$ & 0.19 \\
\hline Respiratory tract & $47(15.6)$ & $39(15.5)$ & $8(16)$ & 1 \\
\hline Urinary tract & $22(7.3)$ & $20(8)$ & $2(4)$ & 0.56 \\
\hline Bone/soft tissue & $19(6.3)$ & $19(7.6)$ & 0 & 0.05 \\
\hline Other & $11(3.7)$ & $9(3.6)$ & 2 (4) & 1 \\
\hline \multicolumn{5}{|l|}{ Source of admission } \\
\hline Operation room & $192(63.8)$ & $159(63.3)$ & $33(66)$ & 1 \\
\hline Ward & $47(15.6)$ & $35(13.9)$ & $12(24)$ & 0.09 \\
\hline Emergency room & $20(6.6)$ & $19(7.6)$ & 1 (2) & 0.22 \\
\hline Other source & $42(14)$ & $38(15.2)$ & $4(8)$ & 0.26 \\
\hline SAPS II (pts) & $43 \pm 15$ & $40 \pm 13$ & $57 \pm 18$ & $<0.001^{*}$ \\
\hline Invasive MV present $\mathrm{n}(\%)$ & $270(89.7)$ & $220(87.6)$ & $50(100)$ & $0.004^{*}$ \\
\hline CVVHF present n (\%) & $118(39.2)$ & $85(33.9)$ & $33(66)$ & $<0.001^{*}$ \\
\hline Highest SOFA (pts) & $11.1 \pm 3.6$ & $10.5 \pm 3.5$ & $14 \pm 2.3$ & $<0.001^{*}$ \\
\hline ICU LOS (days) & $9.9 \pm 8.4$ & $10.2 \pm 8.5$ & $8 \pm 7.8$ & 0.09 \\
\hline ICU mortality n (\%) & $50(16.6)$ & n.a. & n.a. & \\
\hline Hospital mortality n (\%) & $67(22.3)$ & n.a. & n.a. & \\
\hline
\end{tabular}

$B M I$ body-mass index; $C O P D$ chronic obstructive pulmonary disease; CRI chronic renal insufficiency; SAPS simplified acute physiology score; MV mechanical ventilation; CVVHF chronic veno-venous hemofiltration; SOFA sequential organ failure score; ICU intensive care unit; LOS length of stay; n.a. not applicable. * Significant difference between survivors and non-survivors. The SOFA score was calculated from worst clinical and laboratory parameters during the intenisve care unit stay. The SAPS II was calculated from worst clinical and laboratory parameters during the first 24 hours after intensive care unit admission. Data are given as mean values \pm SD unless otherwise indicated. were used to check for normal distribution of study variables; this was approximately fulfilled in all parameters. Unpaired Student's $t$-tests and Fisher's exact tests were used as appropriate to compare data between ICU survivors and non-survivors. Logistic regression models were used to investigate the association between ICU mortality (dependent variable) and BMI (covariate). First, a bivariate regression model was calculated to estimate the unadjusted association between BMI and ICU mortality. Second, to estimate the independent association between BMI and ICU mortality a multivariate model was computed and included BMI and the following confounding factors as continuous or categorical covariates: admission year, age, sex, presence of any heart disease and/or chronic renal insufficiency, number of premorbidities, origin of sepsis and the SAPS II. Two models were calculated for evaluation of the association between BMI categories (underweight, normal weight, overweight, obesity) and ICU mortality: first, a chisquared test was applied to estimate unadjusted differences in ICU mortality between the four BMI categories; second, the multivariate logistic regression model was re-calculated including BMI grouped into four categories as a categorical covariate. $P$-values $<0.05$ were considered to indicate statistical significance. Data are given as mean values \pm SD unless otherwise indicated.

\section{Results}

During the observation period 301 patients with septic shock were identified and enrolled into the statistical analysis (Fig. 1). Characteristics of the study cohort are given in Table 1. In comparison with ICU survivors, the non-survivors were older, taller, weighed less, had lower BMI, suffered more frequently from any heart disease and chronic renal insufficiency, had higher SAPS II and SOFA score, and required invasive mechanical ventilation and continuous veno-venous hemofiltration more frequently (Table 1).

A histogram of the distribution of BMI in the study cohort is shown in Fig. 2. In the bivariate model, high BMI was associated with low ICU mortality and vice

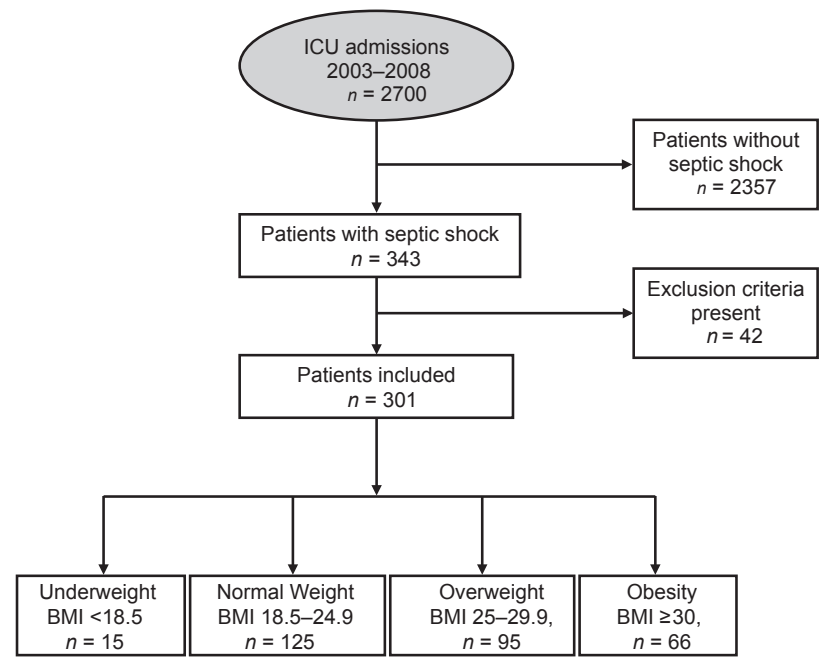

Fig. 1. Selection of study patients and numbers of patients in different BMI categories. ICU intensive care unit; $B M I$ body-mass index. Exclusion criteria: age $<18$ years, $n=18$; pregnancy, $n=1$; no BMI documented, $\mathrm{n}=23$ 


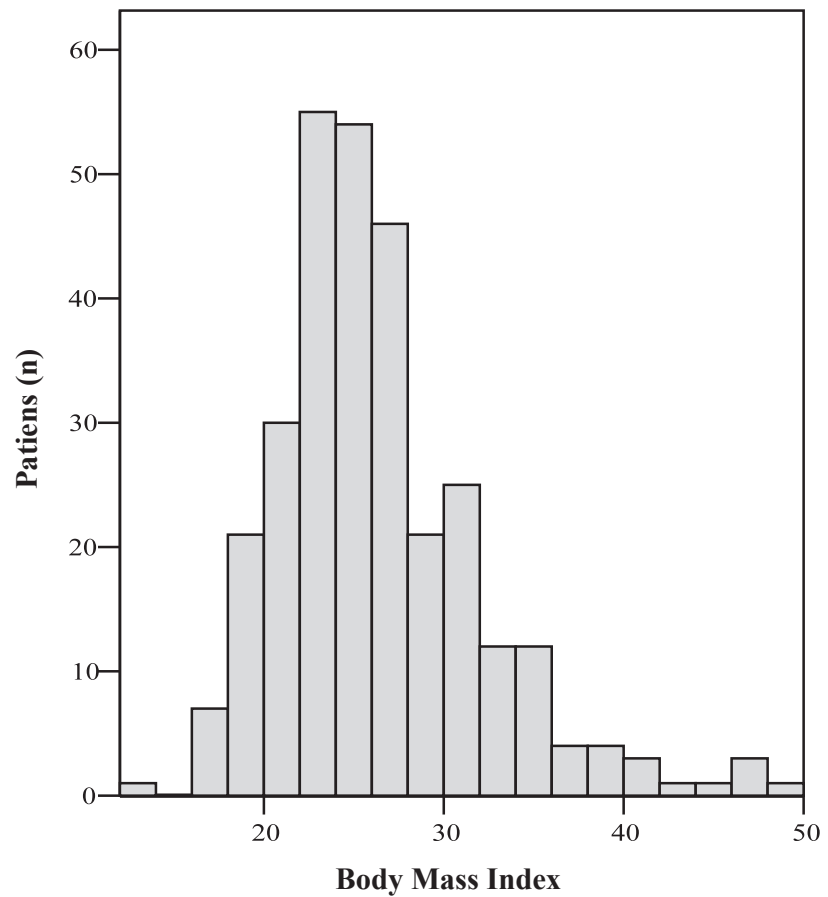

Fig. 2. Numbers of study patients with different body-mass indices

versa (Table 2, Fig. 3). There was no significant association between BMI and ICU mortality in the multivariate model but increasing BMI tended to be associated with lower ICU mortality (Table 2). The association between BMI and mortality did not change after entering the SOFA score as a covariate into both models (bivariate model: OR 0.89; 95\% CI 0.83-0.96; $P=0.004$; multivariate model: OR 0.92; 95\% CI 0.84-1.003; $P=0.06$ ).

Although overweight and obese patients with septic shock had a lower risk of dying in the ICU than septicshock patients with normal weight, there was no differ-

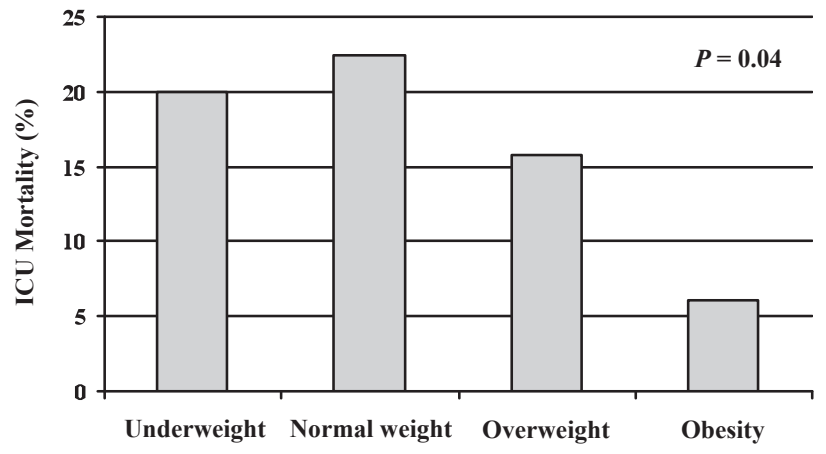

Fig. 3. Intensive care unit mortality in different body-mass index categories. ICU intensive care unit. Underweight, $\mathrm{BMI}<18.5$; normal weight, BMI 18.5-24.9; overweight, BMI 25-29.9; obesity, $\mathrm{BMI} \geq 30$

ence in the risk of ICU death between normal weight and underweight patients (Table 3). High BMI was independently associated with lower frequency of acute delirium and lower need for ICU re-admission but with a higher rate of ICU-acquired urinary tract infections. BMI was not associated with any other secondary outcome variable (Table 4).

\section{Discussion}

In this retrospective cohort study we could not detect an independent association between BMI and septicshock mortality. In a multivariate logistic regression model, overweight and obese patients exhibited a lower risk of dying in the ICU than septic-shock patients with normal BMI. High BMI was independently associated with lower frequency of acute delirium, lower rate of ICU re-admission, higher occurrence of ICU-acquired urinary tract infection, but with no other variable of secondary outcome.

Table 2. Bi- and multivariate models evaluating the association between BMI and ICU mortality

\begin{tabular}{lllllll} 
& Variable Type & Unit & Wald & $\mathbf{O R}$ & $\mathbf{9 5 \%} \mathbf{C l}$ & $\boldsymbol{P}$-value \\
\hline $\begin{array}{l}\text { Bivariate Model } \\
\text { BMI }\end{array}$ & Continuous & & & & & \\
Multivariate Model & & 7.19 & 0.91 & $0.86-0.98$ & $0.007^{*}$ \\
SAPS II & Continuous & (pts) & 25.26 & 1.07 & $1.04-1.1$ & $<0.001^{*}$ \\
Admission year & Continuous & (year) & 3.55 & 1.3 & $0.99-1.71$ & 0.06 \\
BMI & Continuous & & 2.87 & 0.93 & $0.86-1.01$ & 0.09 \\
CRI & Categorical & & 2.77 & 2.06 & $0.88-4.8$ & 0.1 \\
Age & Continuous & (years) & 1.34 & 1.02 & $0.98-1.06$ & 0.25 \\
Premorbidities & Continuous & (n) & 0.18 & 1.06 & $0.75-1.49$ & 0.75 \\
Male sex & Categorical & & 0.04 & 0.93 & $0.44-1.94$ & 0.84 \\
Origin of sepsis & Categorical & & 0.04 & 1.02 & $0.82-1.29$ & 0.84 \\
Heart disease & Categorical & & 0.01 & 1.04 & $0.41-2.63$ & 0.94 \\
\hline
\end{tabular}

$B M I$ body-mass index; ICU intensive care unit; $O R$ odds ratio; $C I$ confidence interval; SAPS simplified acute physiology score; $C R I$ chronic renal insufficiency. Variables are ranked (top to bottom) according to the value of the Wald statistics. *Significant association with ICU mortality. 
In the statistical analysis we applied a multivariate model to exclude the influence of potentially confounding variables on the association between BMI and ICU outcome. We deliberately chose not to include other confounding factors developing $>24$ hours after ICU admission (for example, need for mechanical ventilation or continuous veno-venous hemofiltration) because they may be a direct or indirect consequence of BMI. Although our models were adjusted for eight relevant covariates, we cannot exclude the possibility that unknown variables such as ICU pre-treatment could have influenced the investigated association between BMI and outcome of septic shock.

Our hypothesis that higher BMI was associated with excess mortality in septic shock could not be confirmed. On the contrary, overweight patients had a lower death rate than those of normal weight. Although not statistically significant, the multivariate regression model similarly indicated an independent trend towards lower ICU mortality in septic-shock patients with high BMI. However, when interpreting these findings, it should be kept in mind that our cohort predominantly included normal weight or overweight patients and comparatively few with obesity or morbid obesity (Fig. 1). In addition, several patients categorized as being obese had a BMI close to 30 (Fig. 1), suggesting that small changes in BMI or the definition of higher BMI categories may have changed our results. Thus, no firm conclusions for patients with a BMI $\geq 40$ and no conclusions at all for septic-shock patients with a BMI $\geq 50$ can be drawn from our results. Morbid obesity and particularly a BMI $\geq 50$ have been reported as independent risk factors for death in critically ill surgical patients [13] and may also be associated with increased mortality from septic shock.

Although our results contradict the findings of two experimental studies [8, 9] and a clinical study evaluating the impact of obesity on outcome in patients with bacteremia [7], they are in line with recent publications reporting no effects or even beneficial effects of high BMI on outcome in adult ICU patients. Similarly to our findings, overweight and obesity have been associated with a lower risk of death in ICU [14-20], hemodialysis [21] and in mechanically ventilated patients [22]. Other authors,

Table 3. Body-mass index categories and their association with ICU mortality

\begin{tabular}{lllcl} 
BMI category & BMI range & OR & $\mathbf{9 5 \%} \mathbf{C l}$ & $\boldsymbol{P}$-value \\
\hline Underweight & $<18.5$ & 0.32 & $0.05-1.95$ & 0.22 \\
Normal weight & $18.5-24.9$ & \multicolumn{2}{c}{ Reference } & 0.06 \\
Overweight & $25-29.9$ & 0.43 & $0.19-0.98$ & $0.04^{*}$ \\
Obesity & $\geq 30$ & 0.28 & $0.08-0.93$ & $0.04^{*}$ \\
\hline
\end{tabular}

$B M I$ body-mass index; ICU intensive care unit; $O R$ odds ratio; $C /$ confidence interval. * Significant lower risk of ICU death when compared with patients of normal weight. The logistic regression model was adjusted for admission year, sex, age, presence of heart disease or chronic renal insufficiency, the number of pre-morbidities, origin of sepsis and the simplified acute physiology score II. however, have observed an unchanged [23] or higher ICU mortality in obese patients [24] and in those moderately overweight (BMI >27) [25]. Goulenok et al. [24] adjusted their multivariate model for only three covariates and included ICU length of stay as a covariate that may show some degree of collinearity with BMI [10], whereas Bercault et al. attributed excess mortality rates in obese mixed medical-surgical ICU patients to a higher rate of ICU-acquired complications [25]. In our septic-shock population, no association could be detected between BMI and the rate of ICU complications or ICU-acquired infections, except for urinary tract infection. This may possibly explain the different findings of our and the latter analysis. A recent meta-analysis and a large retrospective analysis, each including $>60,000$ critically ill patients, concluded that obesity was not associated with excess ICU or hospital mortality [10, 26]. The lowest risk of death was observed in ICU patients with BMI $\sim 30$ [10]. Another study reported the lowest risk-adjusted odds ratio for hospital mortality in adult critically ill patients with acute lung injury and BMI of 40 [22].

Interestingly, high BMI was not associated with a greater number of ICU complications in our cohort but

Table 4. Association between BMI and secondary outcome variables

\begin{tabular}{|c|c|c|c|c|}
\hline Linear regression models & $n$ & $\mathbf{R} \mathbf{C}^{\star \star}$ & $95 \% \mathrm{CI}$ & $P$-value \\
\hline Length of invasive MV (days) & 270 & 0.05 & $-0.1-0.2$ & 0.49 \\
\hline Length of ICU stay (days) & 301 & 0.03 & $-0.15-0.21$ & 0.74 \\
\hline Maximum SOFA score (pts) & 301 & 0.04 & $-0.03-0.1$ & 0.29 \\
\hline Logistic regression models & $n$ & $\mathbf{O} \mathbf{R}^{\star \star}$ & $95 \% \mathrm{Cl}$ & $\boldsymbol{P}$-value \\
\hline \multicolumn{5}{|l|}{ ICU complications } \\
\hline Myocardial ischemia & 151 & 1.01 & $0.96-1.06$ & 0.79 \\
\hline Sudden cardiac arrest & 4 & 1.11 & $0.83-1.48$ & 0.49 \\
\hline Acute delirium & 85 & 0.95 & $0.9-1$ & $0.04^{*}$ \\
\hline $\begin{array}{l}\text { Critical illness } \\
\text { polyneuropathy }\end{array}$ & 29 & 1.03 & $0.95-1.12$ & 0.44 \\
\hline \multicolumn{5}{|l|}{ ICU-acquired infections } \\
\hline Urinary tract infection & 22 & 1.1 & $1.02-1.2$ & $0.02^{*}$ \\
\hline Pneumonia & 14 & 0.95 & $0.84-1.08$ & 0.46 \\
\hline $\begin{array}{l}\text { Catheter-related } \\
\text { bloodstream } \\
\text { infection }\end{array}$ & 9 & 1.07 & $0.93-1.23$ & 0.34 \\
\hline $\begin{array}{l}\text { Need for invasive } \\
\text { mechanical ventilation }\end{array}$ & 270 & 1.02 & $0.95-1.09$ & 0.66 \\
\hline Need for tracheotomy & 56 & 0.99 & $0.93-1.06$ & 0.85 \\
\hline Need for ICU re-admission & 34 & 0.87 & $0.8-0.95$ & $0.001^{*}$ \\
\hline Hospital mortality & 67 & 0.95 & $0.89-1.02$ & 0.17 \\
\hline
\end{tabular}

$B M I$ body-mass index; $R C$ regression coefficient; $C l$ confidence interval; MV mechanical ventilation; ICU intensive care unit; SOFA sequential organ failure assessment; $O R$ odds ratio. *Significant association with the body mass index. ${ }^{* *}$ adjusted regression coefficients or odds ratios. Single regression models were adjusted for admission year, sex, age, presence of heart disease or chronic renal insufficiency, the number of premorbidities, origin of sepsis and the simplified acute physiology score II. 
was protective against development of acute delirium and need for ICU re-admission. This is striking, considering that other authors have reported a more frequent and prolonged need for mechanical ventilation, longer ICU and hospital stays, and more infectious complications in obese critically ill patients [10, 23, 26-27]. The specific patient population and the comparatively small number of patients in our analysis might explain why we did not observe such an association. Furthermore, the absence of study patients with $\mathrm{BMI}>50$, known to be particularly prone to develop complications [13], could be another reason for the discrepancy between our results and the current literature. Nonetheless, other authors have similarly observed no difference in the nosocomial infection rate between obese and nonobese patients [14, 18].

The most important limitation of our study is its retrospective design. Even though most variables were extracted from a prospectively collected, validated ICU and hospital database, our results need confirmation in a prospective clinical study. Such a study should also focus on the influence of BMI on mortality rates after hospital discharge. Further, body mass and height in our patient population were not routinely measured using standardized techniques at ICU admission; results of the last available measurement before critical illness or at hospital admission were used instead. Although this strategy may not accurately reflect the true BMI of critically ill patients at the time of ICU admission, it does prevent under- or overestimation of an individual's usual body mass as a result of acute changes due to dehydration or edema formation during critical illness leading to ICU admission. Lastly, we cannot exclude that BMI values of study patients documented in our database were estimated, and not measured accurately.

In summary, BMI up to 50 does not appear to be associated with worse ICU and hospital mortality in patients with septic shock. On the contrary, high BMI may reduce the risk of death from septic shock.

\section{Competing interests}

No author has a conflict of interest regarding techniques or methods discussed in this manuscript. There was no funding source for this research.

\section{References}

1. Ogden CL, Carroll MD, Curtin RL, et al (2006) Prevalence of overweight and obesity in the United States, 1999-2004. JAMA 295: 1549-1555

2. Angus D, Linde-Zwirble WT, Lidicker J, Clermont G, Carcillo J, Pinsky MR (2001) Epidemiology of severe sepsis in the United States: analysis of incidence, outcome and associated costs of care. Crit Care Med 29: 1303-1310

3. Hedley AA, Ogden CL, Johnson CL, Carroll MD, Curtlin LR, Flegal KM (2004) Prevalence of overweight and obesity among US children, adolescents, adults, 1999-2002. JAMA 291: 2847-2580

4. Reinhart K, Brunkhorst F, Bone H, et al (2006) Diagnosis and therapy of sepsis: guidelines of the German Sepsis Society Inc. and the German Interdisciplinary Society for Intensive and Emergency Medicine. Anaesthesist 55 [Suppl 1]: 43-56
5. Calle EE, Thun MJ, Petrelli JM, Rodriguez C, Heath CW Jr (1999) Body weight and mortality in a prospective cohort of US adults. N Engl J Med 341: 1097-1105

6. Festa A, D'Agostino R, Williams K, et al (2001) The relation of body fat mass and distribution to markers of chronic inflammation. Int J Obes Relat Metab Disord 25: 1407-1415

7. Huttunen R, Laine J, Lumio J, Vuento R, Syrjänen J (2007) Obesity and smoking are factors associated with poor prognosis in patients with bacteraemia. BMC Infect Dis 7: 13

8. Singer G, Stokes KY, Terao S, Granger DN (2009) Sepsisinduced intestinal microvascular and inflammatory responses in obese mice. Shock 31: 275-279

9. Vachharajani V, Russell JM, Scott KL, et al (2005) Obesity exacerbates sepsis-induced inflammation and microvascular dysfunction in mouse brain. Microcirculation 12: 183-194

10. Akinnusi ME, Pineda LA, El Solh AA (2008) Effect of obesity on intensive care unit morbidity and mortality: a meta-analysis. Crit Care Med 36: 151-158

11. Levy MM, Fink MP, Marshall JC, et al (2003) 2001 International Sepsis Definitions Conference. Crit Care Med 31: $1250-1256$

12. World Health Organization: Physical status: the use and interpretation of anthropometry: report of a WHO expert committee. WHO Tech Rep Ser 854, Geneva, 1-452

13. Nasraway SA Jr, Albert M, Donnelly AM, et al (2006) Morbid obesity is an independent determinant of death among surgical critically ill patients. Crit Care Med 34: 964-970

14. Frat JP, Gissot V, Ragot S, et al (2008) Impact of obesity in mechanically ventilated patients: a prospective study. Intensive Care Med 34: 1991-1998

15. Kershaw EE, Flier JS (2004) Adipose tissue as an endocrine organ. J Clin Endocrinol Metab 89: 2548-2556

16. Galanos AN, Pieper CF, Kussin PS, et al (1997) Relationship of body mass index to subsequent mortality among seriously ill hospitalized patients. Crit Care Med 25: 1962-1968

17. Garrouste-Oregas M, Troché G, Azoulay E, et al (2004) Body mass index. An additional prognostic factor in ICU patients. Intensive Care Med 30: 437-443

18. El-Solh A, Sikka P, Bozkanat E, Jaafar W, Davies J (2001) Morbid obesity in the medical ICU. Chest 120: 1989-1997

19. Druml W (2008) ICU patients: fatter is better? Intensive Care Med 34: 1961-1963

20. Druml W (2007) Reverse epidemiology - do obese patients have a better prognosis? Wien Klin Wochenschr 119: 617-619

21. Kotanko P, Kuhlmann WK, Levin NW (2007) Why obese dialysis patients live longer - a hypothesis. Wien Klin Wochenschr 119: 620-624

22. O'Brien JM, Phillips GS, Ali NA, Lucarelli M, Marsh CB, Lemeshow $S$ (2004) Body mass index is independently associated with hospital mortality in mechanically ventilated adults with acute lung injury. Crit Care Med 34: 738-744

23. Sakr Y, Madl C, Filipescu D, et al (2008) Obesity is associated with increased morbidity but not mortality in critically ill patients. Intensive Care Med 34: 1999-2009

24. Goulenok C, Monchi M, Chiche JD, Mira JP, Dhainaut JF, Cariou A (2004) Influence of overweight on ICU mortality. Chest 125: 1441-1445

25. Bercault N, Boulain T, Kuteifan K, Wolf M, Runge I, Fleury JS (2004) Obesity-related excess mortality rate in an adult intensive care unit: a risk-adjusted matched cohort study. Crit Care Med 32: 998-1003

26. Tremblay A, Bandi V (2003) Impact of body mass index on outcomes following critical care. Chest 123: 1202-1207

27. Yaegashi M, Jean R, Zuriqat M, Noack S, Homel P (2005) Outcome of morbid obesity in the intensive care unit. J Intensive Care Med 20: 147-154 